\title{
A Research on Light-Color Perception: Can Visual Images Be Used Instead of 1/1 Model Study for Space Perception?
}

\author{
Banu Manav \\ Department of Interior Architecture and Environmental Design, Faculty of Art and Design, \\ İstanbul Kültür University, İstanbul, Turkey \\ Email:b.manav@iku.edu.tr
}

Received July $10^{\text {th }}, 2013$; revised August $6^{\text {th }}, 2013$; accepted August $29^{\text {th }}, 2013$

\begin{abstract}
Copyright $\odot 2013$ Banu Manav. This is an open access article distributed under the Creative Commons Attribution License, which permits unrestricted use, distribution, and reproduction in any medium, provided the original work is properly cited.
\end{abstract}

\begin{abstract}
This paper examines designing a research on architectural coloring process and approaches to develop a color-emotion space model for human visual system. Matched on relevant methodology, a study is explored to compare modes of color evaluation with the following hypothesis; can slides of a real setting be used instead of 1/1 model study for space perception? The study is composed of two interrelated parts. Firstly, 1/1 model room is designed in order to investigate lighting quality, color evaluation and visual perception in respect to the lighting scheme. Secondly, slides of this model room are projected to a participant group to evaluate the room for lighting quality, color evaluation and visual perception. The methodology is based on investigating between the two cases. The $1 / 1$ scaled model and replication of the same study by its slides are analyzed from lighting quality and lighting quantity point of views. The findings suggested that there are similarities between the results, however the 1/1 model room provides a controlled setting for human based research, visual impact is stronger and subjective impression is more realistic. As a visual research method, replication of a real setting (by its slides) can be used instead of constructing the real case which may also bring flexibility and lower cost to design studies.
\end{abstract}

Keywords: Architecture; Color Modelling; Color Space; Cognitive Color; Visual Perception

\section{Introduction}

Light and color perception in architecture address theoretical and methodological issues in regard to an individual's perceptive and psychological functions as well. As recent research has consistently shown that light entering the human eyes has an important non-visual biological effect on the human body, its influences on human health, well-being and productivity at the work environment are an important issue to be studied (CIE, 2005; Sanoff, 1991). Parallel to this argument, in the works of various researchers, qualitative rather than the quantitative aspects of the luminous environment have been studied (Pultar, 2000; Farnsworth Manual, 2012; Manav, 2007; Kaya \& Crosby, 2006; Ural \& Yılmazer, 2010; Camgöz et al., 2002; Ou et al., 2004a; Ou et al., 2004b; Xin et al., 2004a; Xin et al., 2004b). In these works, it is mostly aimed to solve problems related to visibility (physiological needs) and psychological comfort (health, well-being, mood, alertness et cetera).

Therefore, lighting design and architectural coloring studies comprise research methods such as full scale model work, CAD modelling which stand as a forum for professionals, clients, students and researchers to discuss and develop basic issues related to light color perception. In spite of the empirical research and knowledge which attempt to describe color-emotion models, people environment relations and color-light interaction on user comfort, the need for reconsideration of literature within an architectural context is inevitable. In order to design a research on architectural lighting and coloring process and also to develop a guide for space perception for human visual system, a holistic approach to the era is essential where quantitative and qualitative components in human perception system shall be evaluated together.

The presented article addresses a research and an evaluation on light color studies in interior architecture. Modes of cognitive color evaluation and color appearance in regard to lighting design are based on various factors for which different measuring techniques are developed. In the study, a case study is discussed with the following research problem; can slides of a real setting be used instead of $1 / 1$ model study for space perception?

\section{Space Perception and Light-Color Studies}

Perception is defined as the immediate mapping of objects into the brain while cognition refers to subsequent processs of semantic and verbal classification of perception (CIE, 2005). Perception in interior architecture depends on the visual cues of the physical space, in other words, the characteristics of the visual environment, such as size, shape, texture, color, position of the object to the viewer (Sanoff, 1991). At this level, light as a physical sensor from the immediate environment activates the physical process and ends up with the psychological space. We interpret the color scheme-lighting level, furniture style and other interior design elements as indicators of personal judgments, such as complex, spacious, private, relaxing et cetera. As a result of short term or long term impressions, we can also identify the nature of the spaces that depend on the judgment of 
their quality and status.

Collectively, elements of the physical environment not only form a setting, but also are a part of the experience of being there, in that particular setting. For instance, light and color influences our perception of temperature which is a parameter for an appealing environment in psychological process (Figure 1). It can create comfortable situations (warm/hot) or the opposite, the uncomfortable situations (cold). Similarly, the same space can be perceived distracting, hazy, dull, unspacious, intraverted or vice versa, bright, relaxing, spacious, extraverted in regard to the color scheme together with lighting. As being an indicator of visual perception, light can evoke or subdue visual comfort conditions. People have personal experiences and inherent beliefs some of which are associated with culture, age, gender as well. These parameters together make up the lightcolor emotion space. Figure 1 illustrates how physical environment activates human perception system with an emphasis on factors which are affective on space perception mechanism.

An important aspect of architectural space is man's involvement in its generation and his partaking of life in it. In this sense, a research on space perception shall be designed in relation to our way of understanding the surrounding. It shall depend on a set of visual cues which is developed from knowledge-based systems and cognitive beliefs as well (Pultar, 2000). Symbols and cognitive schemata affect human perception as they form the essence of man's knowledge. These are all part of knowledge-based system which can be broken down into five categories; starting with a research question, type of research, methodology, data recording type and data analysis. Similarly evaluation of lighting on user satisfaction is related to cognitive beliefs, gender, culture which all have been studied before.

\section{Model Workshop Studies}

\section{Scaled Models}

Architectural design process also flows from a series of studies which bring into open the subconcious. Full scale color model

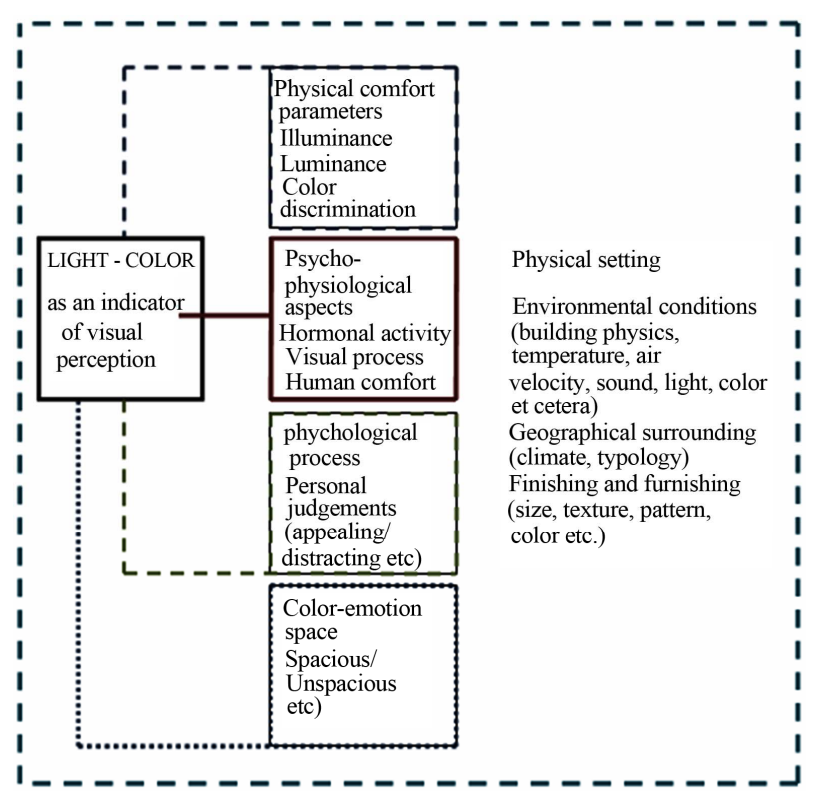

Figure 1.

Human perception system and factors affecting the architectural lighting-coloring process. workshop is the representation and simulation of the real case conditions. It is an effective tool to analyse and to evaluate light-color-mood association and preference. As being similar to the real case conditions, it is reductive, it also targets a theme or a research problem such as structure, space-form, light, color, sound and environmental quality (Morris, 2006). The model workshop also helps to achieve a coincidence between the intended and finalized design idea while investigating an optimal fit between the user group and the designed environment (Sanoff, 1991). Each of the parameters in the model setting is in their original scale and it is easy to set up a controlled research. Results of many studies can provide cues to enhance the importance of full scale model workshop in architectural design process and to study human perception system.

Full scale model workshop has generated light and color research issues many years ago and many researchers still take a great interest in it. Starting from 1970's onwards, different issues such as quality of light, light-color interaction and user comfort have gained importance. These are related to the quality of life that aim to eliminate factors such as sick building syndrome, post occupancy evaluation, design quality indicator et cetera, meanwhile, trying to improve user's well-being, motivation and performance.

Lund Simulator, which is one of the best known full scale model workshops, is developed by Janssens and Küller in order to investigate and to evaluate human perception system in regard to the physical environment. This is helpful to evaluate and to understand how color in a particular interior is an affective component of visual perception, on behaviour and on comfort. There are relevant studies which aim to investigate the difference between the results of full scale model works and their replication through the slides of the same model. Results clearly indicate that, the real case setting (constructed one) and the slide view (unconstructed one) are different by means of visual perception (Flynn et al., 1992; Manav \& Küçükdoğu, 2008). Though there are similarities between full scale model work and simulation of the real case by the pictures and/or slides, the results can not be generalized due to the fact that the difference in perception between the constructed and the unconstructed. Also, as Kwallek and his colleagues have stated, viewing color pictures/slides of a particular interior is not realistic (Kwallek et al., 2006). They suggest that, people shall be exposed to real interior environments which are more realistic to evaluate subjective responses. For instance afterimages can also occur in real case settings by affecting the perceived color scheme, which is not possible in the unconstructed one.

\section{Simulation Research}

Since the beginning of 1990 s, computer aided manufacture (CAM) has made it possible to translate computer designs into three dimensional forms (Morris, 2006). Environmental simulation studies via video screens, virtual reality, CAD modelling could also be advisable. However, these simulation methods provide to analyse psycho-physical components without constructing them. Yet, lighting effects and color evaluation is completed under real-case settings where light-color interaction is an important parameter, as well as, interreflections through which three attributes of color (hue,value, saturation) may be effective on human perception system, as well as the illuminance, luminance, constract factor of the lit environment.

CAD modelling, Cave (Computer Assisted Virtual Environ- 
ment) and similar 3D modelling programs are developed in response to a challenge to perceive the unbuilt environment, to conduct research in various virtual reality settings and scientific visualization fields. However, light-color perception is the result of experiencing it and is accompanied by associated meanings. These programs are helpful to experience the unbuilt environment, as they can enable participants to meet in a virtual space, however they are not the real case.

\section{Psychophysical Experiments In-Between}

Psychophysical experiments are conducted to investigate light-color-mood association, lighting effects, color appearance of small color sample studies in full scale models where environmental conditions are influential design parameters. For example, Tangkijviwat et al. (2010) argued that, a color could be perceived as a property of a surface when its luminance level was quite low. Secondly, it was perceived as a property of light source or light itself (for example self-radiating) when its luminance level was adequately high. Thirdly, its mode was quite ambiguous because it possessed both surface and light quality. They named these conditions as the mode object (OB-mode), light source (LS-mode), and unnatural object (UN-mode), respectively. Their findings showed that the color chips with high chroma and high brightness yielded high scores, hues had a small effect on color preference and the light source was an important parameter to define color preference. They also found that color appearance mode had an influence over color preference. This supports Manav et al.'s findings which indicated that color associations seem to rely on individuals' previous knowledge and experience. Color preferences change when they are observed as a color set. The difference may be as a result of the color properties or as a result of the light source. It is advised to study chromatic-achromatic adaptation together with the light source to have more reliable interior spaces (Xiao et al., 2010). These studies highlight the importance of the light scheme as a design parameter in order to investigate color preferences, psychological and psychophysical aspects of color. As indicated in Ural and Yilmazer (2010), Stahre et al. argued that colors are perceived more distinct and stronger in a full-scale room.

Xiao et al. (2010) investigated the size effect of color appearance between small color samples and full scale models. In the study, the walls were painted by 12 different colors and were assessed using 2 different matching media: CRT and NCS color atlas under two different light sources. CIECAM02 was used in transforming XYZ tristimulus values to human perceptual attributes: lightness, chroma, hue. The experimental data show a clear trend that a color becomes lighter and more colorful when its physical size is increased. It is also found that these effects are independant of the light source. However, Manav et al. compared the appraisal of a full scale model with respect to 3 dependable variables versus 4 different wall colors, illuminance and color rendering of the light sources (2009). According to the results, illuminance and color temperature are influential on personal evaluation factor, spatial evaluation factor and factor of originality separately (Manav et al., 2009; Manav et al., 2010).

Studies of physiological and psychological effects of full scale colored room interiors on people indicate that coloring in an interior space has effects on different levels. Human perception system is affected by the room interior, also the color schema has effects on the emotions and physiology as described in Figure 2. As indicated in Küller et al. chromatic effects of red (strong, vivid) has put the brain into a more excited state, event that causes a paradoxical slowing of the heart rate. Introvert people have affected strongly in comparison to the extraverted ones which cause severe changes in their performance as well (Küller et al., 2008; Küller, 1970; CIBSE, 1984). Good color design serves to improve the overall mood and well-being of people such as brain activity, mood and performance.

\section{The Hypothesis}

As mentioned before, modes of light-color evaluation and appearance of the lit environment can be compared via various methods. In the present study, the responses of the participant group for $1 / 1$ scaled model and the replication of the same study by the slides are compared, with a particular emphasis on visual perception and color evaluation.

The differences and similarities between two different visual research appraisal of the visual environment in relation to lighting quality and color evaluation are evaluated with the following hypothesis; can slides of a real setting be used instead of $1 / 1$ model study for space perception?

\section{The Methodology}

The methodology is based on investigating the $1 / 1$ scaled model and replication of the same study by its slides. These two cases are analyzed from lighting quality and lighting quantity point of views. The study is conducted in two parts. In the first part, a 1/1 model is designed where a series of studies on lighting quality, color evaluation and visual perception are investigated. The lighting system is operated by an automatic lighting control system where lighting level can be controlled, so does the luminance values.

The full scale model is a windowless room with no daylight penetration. In the model study, 56 participants are asked to evaluate the visual appeal of the room in regard to lighting

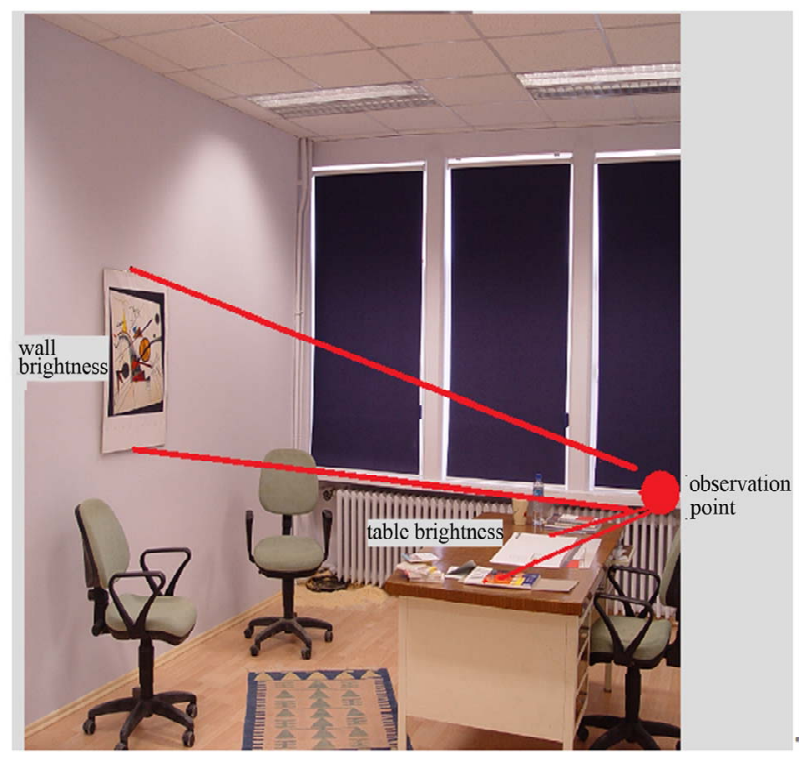

Figure 2.

The test room, observation point, general view. 
settings (1000 lx, 750 lx, $500 \mathrm{~lx}$ and $4000 \mathrm{~K}$ versus $2700 \mathrm{~K}$; a total of 6 lighting settings as seen in Table 1) and color appearance of the objects. Contrast factor is calculated and visual appeal of the surrounding is evaluated. Figure 2 and Table 1 illustrate observation point and the measured points A, B, C and $\mathrm{D}$. Slides of the model room is projected on a white roller blind at a windowless room.

Following this, in the slide view study, replication of the model study is conducted with 36 university students who are asked to evaluate a series of the slides in two parts, according to vision (lighting quantity) and psychological (lighting quality) aspects of lighting installations. The participants are free to view the lighting alternatives until they decide on the most satisfactory one. In case none of the lighting alternatives are satisfying the tested parameter, they are asked to mention as "no difference".

\section{The Model Study Measurements}

In the first part; luminance values for different points on the table are recorded under each of the lighting setting. Contrast factor analyses are measured which are given in Table $\mathbf{1}$.

The results indicate that, there is no glare for points $\mathrm{A}$ and $\mathrm{B}$ with respect to the reference lighting setting (referred as $750 \mathrm{~lx}-$ $4000 \mathrm{~K}$ according the results of a previous study (Manav and Küçükdoğu, 2008) and in regard to the CIBSE Standards (1984), however there is a problem from lighting quantity point of view for the points $\mathrm{C}$ and $\mathrm{D}$ due to the reason that the calculated contrast value is above 1.00. As glare diminishes the quality of space perception, visual performance is affected negatively.

\section{Comparing Model Study and Slide View; Lighting Quantity}

The effect of lighting quantity on visual perception and color evaluation is analyzed by comparing $500 \mathrm{~lx}$ and $2000 \mathrm{~lx}$ illuminance. It is clearly seen that, though responses to the lighting settings are quite similar from visual perception point of view, there are differences between the $1 / 1$ scale model and slide view evaluation.

Visual perception analysis reveals that, for the model evaluation, $2000 \mathrm{~lx}$ is preferred to $500 \mathrm{~lx}$ for the impressions of comfort, being wide and spacious, brightness evaluation of the ob- jects on the table and on the wall, saturation of the objects on the table and on the wall. $500 \mathrm{~lx}$ is preferred only for the impression of relaxation. On the other hand, $500 \mathrm{~lx}$ is preferred for relaxation and comfort for the slide simulation (indicated as $\mathrm{S}$ in Figure 3). For the rest of the impressions, $2000 \mathrm{~lx}$ has got higher percentage.

Depending on the change in the illuminance, saturation level on the object surfaces which are located on the table and on the wall opposite to the view point increased which also affects the visual appeal of the surrounding positively, so does the color appearance. Similarly, when the space is viewed by slides, the sudden change in the illuminance has also affected the visual appeal and color perception positively.

As the change in illuminance has affected the brightness evaluation positively, measured luminance values for different points have also increased which in turn is affective on color perception. Color perception depends on luminance values which is mandatory for space perception and evaluation.

\section{Comparing Model Study and Slide View; Lighting Quality}

Firstly visual appeal at the model setting is analyzed and compared in relation to two different color temperatures; $2700 \mathrm{~K}$ and $4000 \mathrm{~K}$. Following this, slides of the model is evaluated by the participant group for $500 \mathrm{~lx}, 750 \mathrm{~lx}$ and $1000 \mathrm{~lx}$ respectively.

The results clearly indicate that, it is not possible to general-

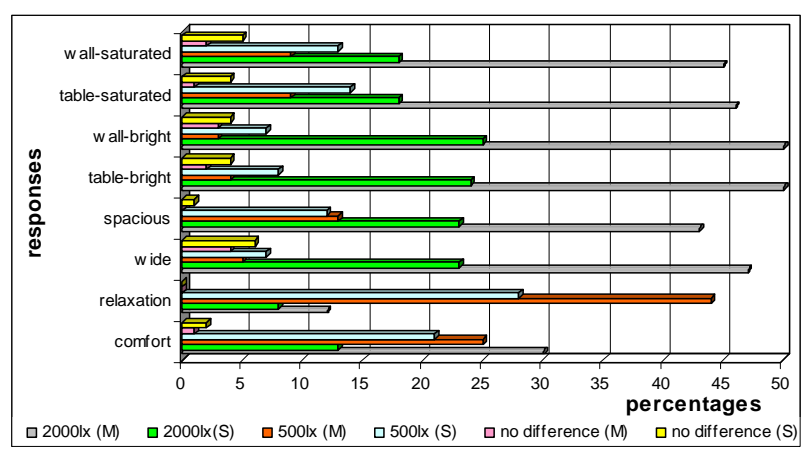

Figure 3.

Comparison of the model and the slide view for lighting quantity.

Table 1.

Luminance values and contrast factor analysis for points A, B, C, D.

\begin{tabular}{|c|c|c|c|c|c|c|}
\hline Lighting setting & Point A black & Point B white & $\left|\mathrm{Lt}_{\mathrm{A}}-\mathrm{Lb}_{\mathrm{B}} / \mathrm{Lb}_{\mathrm{B}}\right|$ & Point $\mathrm{C}$ red & Point D grey & $\left|\mathrm{Lt}_{\mathrm{C}}-\mathrm{Lb}_{\mathrm{D}} / \mathrm{Lb}_{\mathrm{D}}\right|$ \\
\hline $\begin{array}{l}1000 \mathrm{~lx} / \\
4000 \mathrm{~K}\end{array}$ & $22.1 \mathrm{~cd} / \mathrm{m}^{2}$ & $241 \mathrm{~cd} / \mathrm{m}^{2}$ & 0.90829 & $71.1 \mathrm{~cd} / \mathrm{m}^{2}$ & $37.9 \mathrm{~cd} / \mathrm{m}^{2}$ & 0.876 \\
\hline $\begin{array}{l}7501 \mathrm{x} / \\
4000 \mathrm{~K}\end{array}$ & $17.5 \mathrm{~cd} / \mathrm{m}^{2}$ & $191.1 \mathrm{~cd} / \mathrm{m}^{2}$ & 0.90890 & $56.7 \mathrm{~cd} / \mathrm{m}^{2}$ & $31.5 \mathrm{~cd} / \mathrm{m}^{2}$ & 0.8 \\
\hline $\begin{array}{l}500 \mathrm{~lx} / \\
4000 \mathrm{~K}\end{array}$ & $11.8 \mathrm{~cd} / \mathrm{m}^{2}$ & $127.9 \mathrm{~cd} / \mathrm{m}^{2}$ & 0.90703 & $37.5 \mathrm{~cd} / \mathrm{m}^{2}$ & $21.6 \mathrm{~cd} / \mathrm{m}^{2}$ & 0.736 \\
\hline $\begin{array}{l}1000 \mathrm{~lx} / \\
2700 \mathrm{~K}\end{array}$ & $24 \mathrm{~cd} / \mathrm{m}^{2}$ & $260 \mathrm{~cd} / \mathrm{m}^{2}$ & 0.90769 & $128 \mathrm{~cd} / \mathrm{m}^{2}$ & $54 \mathrm{~cd} / \mathrm{m}^{2}$ & 1.37 \\
\hline $\begin{array}{l}750 \mathrm{~lx} / \\
2700 \mathrm{~K}\end{array}$ & $22 \mathrm{~cd} / \mathrm{m}^{2}$ & $206 \mathrm{~cd} / \mathrm{m}^{2}$ & 0.89320 & $101.4 \mathrm{~cd} / \mathrm{m}^{2}$ & $46 \mathrm{~cd} / \mathrm{m}^{2}$ & 1.204 \\
\hline $\begin{array}{l}500 \mathrm{~lx} / \\
2700 \mathrm{~K}\end{array}$ & $17.4 \mathrm{~cd} / \mathrm{m}^{2}$ & $147.3 \mathrm{~cd} / \mathrm{m}^{2}$ & 0.88367 & $60.5 \mathrm{~cd} / \mathrm{m}^{2}$ & $24.3 \mathrm{~cd} / \mathrm{m}^{2}$ & 1.49 \\
\hline
\end{tabular}


ize the results of the $1 / 1$ model and the slide simulation, as there is discrepancy for the color properties of the light sources; $2700 \mathrm{~K}$ versus $4000 \mathrm{~K}$ under $500 \mathrm{~lx}, 750 \mathrm{~lx}$ and $1000 \mathrm{~lx}$ respectively. However, impressions which are related to the physical boundaries of the space have similar influences on the participants. Under $4000 \mathrm{~K}$, the space is perceived as wide and spacious under the three illuminances. Also $2700 \mathrm{~K}$ is preferred for the impression of relaxation under the three illuminances. Model and slide simulation comparisons are similar under 500 $\mathrm{lx}$ and $1000 \mathrm{~lx}$ for comfort $(4000 \mathrm{~K})$, however under $750 \mathrm{~lx}$ there is a discrimination; $4000 \mathrm{~K}$ is preferred for the model while $2700 \mathrm{~K}$ is offerred for the slide simulation. In Table 2, the summary of the results are given. Table 2 illustrates the comparison of the effect of color temperature on space perception.

Saturation depends on the interreflections in a space and it is related to the interaction of a surface by a light source. In the study, saturation level of the colors are compared for two different color temperature under three different illuminance.

Saturation level of the objects on the table and for points A, $\mathrm{B}, \mathrm{C}, \mathrm{D}$ on the poster (on the table) for $2700 \mathrm{~K}$ and $4000 \mathrm{~K}$ has got the same percentage in the model study, while for the slide simulation $4000 \mathrm{~K}$ is preferred under $750 \mathrm{~lx}$ and $1000 \mathrm{~lx}$. When the illuminance is $500 \mathrm{~lx}, 2700 \mathrm{~K}$ is offerred for the model study, while $4000 \mathrm{~K}$ is offerred for the slide simulation for the saturation levels of the objects on the table. Saturation level of the colors on the wall is also evaluated for which both of color temperature has got the same value.

\section{Results and Discussion}

The comparison of the model study and slide views bring into the following results:

- It seems to support the theory that the experience of a lighted space is, to some extent, a shared experience for different measuring techniques. In other words, using slide views of a space is to some extend valid in data collection stage, however it is not the replication of the real setting. Working with real case settings $(1 / 1$ model) is more realistic and the visual impact is higher according to the findings of the study.

- It might be effective to work with different techniques and to improve the results from different perspectives.
Working with different methods and techniques may provide flexibility. Flexibility in design research also helps to shed light on the research problem from various points.

\section{Conclusion}

As explained in Rodeck and Mahnke (2007), concious and subconcious factors play a role in visual perception. Every color stimulus that is illuminated by a light source is recorded from the physical (external) world corresponding with a subjective reaction from the inner world. For this reason, personal reactions to color space shall be studied by the physical process of seeing color and data recording in our brain. Through holistic associations within our sensory system, a particular color is not only a sense of sight, but also a sense of stimuli in the entire context of human perception system. Therefore, its' role on the whole mechanism shall be studied systematically. A systematic research approach shall be developed with a special focus on the methodology.

The present study introduces a research on the differences and similarities between two different visual research methods regarding the appraisal of the visual environment in relation to lighting quality and color evaluation. The slides of a real setting are compared to the slides of the same setting. The results indicate that, to some extent, there is a shared experience for the two measuring techniques. In other words, using slide views of a space to some extend is valid in data collection stage, however it is not the replication of the real setting. Working with real case settings $(1 / 1$ model) is more realistic and the visual impact is higher according to the findings of the study.

While designing a research on architectural coloring, there are various research methods which have their own characteristics and systematic approach. Three dimensional technology gives a better understanding of concept and ideas. Scaled models, especially full scale model workshop is costly and requires a high budget and effort to set up, meanwhile they provide a controlled real setting for human based research, visual impact is strong and subjective impression is based on real case setting. Color sample studies are two dimensional and are efficient for theory development stage. Three dimensional visualization technology gives a deeper understanding of concept and ideas.

A combination of different teaching technology and visuals are beneficial for achieving a better understanding of concepts

Table 2.

The analyses on lighting quality for the model and the slide view.

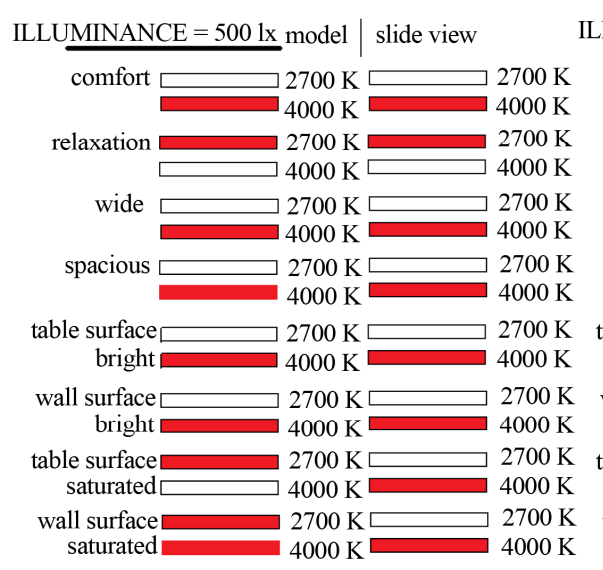

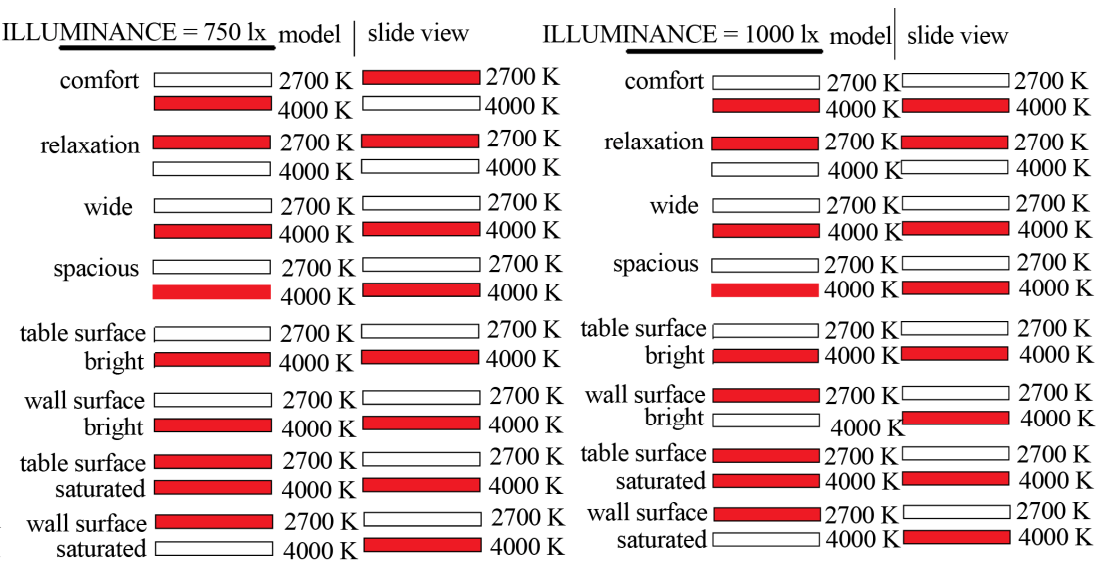


and designs. Working with different methods and techniques may provide flexibility. Flexibility in design research also helps to shed light on the research problem from various points. It is hoped that this paper provides a base to develop an understanding on comparing different methods on space perception. The study can be enlarged by evaluating the simulation of the real case by computer aided technology as well. In addition, semantic differential scale can be adopted to compare different visual research methods and a matrix can be developed.

\section{REFERENCES}

Camgöz, N., Yener, C., \& Güvenç, D. (2007). Effects of hue, saturation, and brightness on preference. Color Research and Application, 27, 199-207. doi:10.1002/col.10051

CIBSE (1984). Code for interior lighting. London: The Chartered Engineers.

CIE (2005). Commission internationale de l'eclairage. Cognitive Color, Research Note. CIE:166:2005 References.

Farnsworth Munsell 100 Hue Test Manual Software v.3.0. Program (2012).

Flynn, J. E. et al. (1992). Interim study of procedures for investigating the effect of light on impression and behaviour. In R. Mark (Ed.), Selected papers on architectural lighting. Washington: SPIE Optical Engineering Press.

Kaya, N., \& Crosby, M. (2006). Color association with different building types: An experimental study on American college students. Color Research and Application, 31, 1-5. doi:10.1002/col.20174

Küller, R. (1970). Perception of an interior as a function of its interior. Proceedings of the Architectural Psychology Conference at Kigston Polytechnic.

Küller, R., Mikellides, B., \& Janssens, J. (2008). Color, arousal and performance; a comparison of three experiments. Color Research and Application, 34, 141-152. doi:10.1002/col.20476

Kwallek et al. (2006). Work week productivity, visual complexity and individual environment sensitivity in three offices of different color interiors. Color Research and Application, 32, 130-143. doi: $10.1002 / \mathrm{col} .20298$

Mahnke, M., \& Rodeck, B. (2007). Color communication in architectural space. Basel: Birkhauser.

Manav, B. (2007). Color-emotion associations and color preferences: A case study for residences. Color Research and Application, 32, 144-
151. doi:10.1002/col.20294

Manav, B., \& Küçükdoğu, M. (2008). Lighting, health, well-being and the work environment. Proceeding Book of Balkan Light Congress, Razsvetljava, 105-112.

Manav, B., Güler, Ö., Onaygil, S., \& Küçükdoğu, M. Ş. (2009). A research on office workers' color preferences: Five color samples under six lighting alternatives. Arkitekt, 520-522, 22-31.

Manav, B., Kutlu, R., \& Küçükdoğu, M. (2010). The effects of color and light on space perception, color and light in architecture. In P. Zennaro (Ed.), Proceeding book of international conference (pp. 173-179). Venero:Cierre Group Editoriale.

Morris, M. (2006). Models: Architecture and the miniature. Great Britain: John Wiley \& Sons.

Ou, L.-C., Luo, M. R., Woodcock, A., \& Wright, A. (2004a). A study of color emotion and color preference. I. Color emotions for single colors. Color Research and Application, 29, 232-240. doi: $10.1002 / \mathrm{col} .20010$

Ou, L.-C., Luo, M. R., Woodcock, A., \& Wright, A. (2004b). A study of color emotion and color preference. II. Color emotions for twocolor combinations. Color Research and Application, 29, 292-298. doi:10.1002/col.20024

Pultar, M. (2000). A structured approach to cultural studies of architectural space. In F. Warwick (Ed.), Ethics and the built environment (pp. 155-169). London: Routledge.

Sanoff, H. (1991). Visual research methods in design. New York: Van Nostrand Reinhold.

Tangkijviwat, U. et al. (2010). Color preference affected by mode of color appearance. Color Research and Application, 35, 50-63. doi: $10.1002 / \operatorname{col} .20536$

Ural, S. E., \& Y1lmazer, S. (2010). The architectural color design process: An evaluation of sequential media via semantic ratings. Color Research and Application, 35, 343-351. doi:10.1002/col.20583

Xiao, K., Luo, M. R., Li, C., \& Hong, G. (2010). Color appearance of room colors. Color Research and Application, 35, 284-293. doi: $10.1002 / \mathrm{col} .20575$

Xin, J. H., Cheng, K. M., Taylor, G., Sato, T., \& Hansuebsai, A. (2004a). A cross-regional comparison of color emotions, part I: Quantitative analysis. Color Research and Application, 29, 451-457. doi: $10.1002 / \mathrm{col} .20062$

Xin, J. H., Cheng, K. M., Taylor, G., Sato, T., \& Hansuebsai, A. (2004b). Cross-regional comparison of color emotions, part II: Qualitative analysis. Color Research and Application, 29, 458-466. doi:10.1002/col.20063 